The Geneva Papers on Risk and Insurance, 20 (No. 77, October 1995) 419-422

\title{
Insurability and the Economic Relevance of Insurance: A Historical Economic Perspective*
}

\author{
by Orio Giarini
}

\section{Once upon a time...}

During the industrial revolution, insurance like many other services was deemed an honorable but secondary activity. The priority was given to the manufacturing process which was the key to increasing the wealth of nations. Adam Smith, the founder of economic theory, relegated most services (and this was right for his times) to an insignificant role in the making of economic (i.e. added) value.

In the century following Adam Smith's death and up to the 2nd World War, the startling success of science and technology gave credence to the idea that any technological or even social uncertainty could be eliminated by knowledge and scientific management, so as to make activities like insurance obsolete. Right across the political spectrum, from left to right, the prevailing ideology held that the future would become ever more predictable and that with it man's capacity to control and avoid all uncertainty, be it related to the functioning of a machine, the distribution of a product or to the organisation of society, would grow.

Uncertainty in economic and social systems was considered a transient imperfection which advances in science and technology would in time eliminate, rendering insurance unnecessary.

There are remnants of such ideas in contemporary society. Culture is a slow process of adaptation. Take, for example, the weather forecast. We still speak of the sun rising and setting. The vocabulary we use contradicts reality, even after the catholic church has officially admitted, recently, that Galileo Galilei was right.

Or take national accounting systems: They consider the value of insurance with reference only to the salaries paid to insurance employees. The compensation paid for instance for a crashed automobile constitutes added value only when it is used to buy a new car. Such "value" is accounted in the manufacturing sector not in insurance, which obscures the fact that if the insurance systems did not exist, many new cars would not be bought. As almost always, the identification and quantification of facts depend on dominant theories (in this case economic theory) which determine priorities according to recognised or at least implicitly accepted sets of ideas.

* Paper presented at the International Insurance Conference, organized in Zurich, on November 28-29, 1994 by Ernst D. Young with the collaboration of the Geneva Association. 
On the other hand, it should also be recognised that, for instance, at the beginning of our century, environment liability, industrial breakdown, pollution, consequential losses, and even social security and health insurance systems to the extent they exist today, were not on the priority list either of governments or of enterprises. Even 50 years ago, up to the 2nd World War, most insurance issues within an industrial company were considered secondary and, as such, commonly handled by a management secretary.

Why bother about secondary or non-essential activities, like insurance and similar services? When in any case, sooner or later, our science-based society will have eliminated all uncertainty...?

\section{And then came 1973...}

The success of modern science and technology became even more apparent after the 2nd World War. For over 25 years, the economic rate of growth for most industrialised nations of the world rose on average by more than $6 \%$ per year over the period as a whole. A unique historical experience without precedent.

But in 1973 there came the first oil shock. It ushered in a period of diminishing growth rates and of inflation. Could it, however, all be explained exclusively in terms of the price of oil per barrel? Simulations made at the most advanced research centres in the world were showing that, considering the amount of oil consumed across the economic fabric, even those staggering increases in prices would in fact, all other things being equal, have added less than $1 \%$ to the total inflation rate. In reality the oil crisis had precisely the effect of a match triggering a fire along a wide front in a forest which factors of preconditioning had made ripe for combustion. What were those factors?

- First, there was the fact that over that period services had, in quantitative terms, become the major type of economic activity even within the manufacturing system. This had modified the conditions of rigidity of supply radically altering the problem of inflation control. The increase in the number and cost of services within the manufacturing system was paradoxically brought about not by inefficiencies within the system itself, but on the contrary, by the very efficiency of the new technological systems which now had to be researched, developed, financed, maintained, controlled, etc.

- The second factor was the growth of vulnerability, first in the manufacturing system. Here again, the situation was paradoxically created by the efficiency of new technologies. On the one hand specialisation made risk classes smaller and smaller and increasingly differentiated, while good technology reduced the likelihood of negative events occurring. On the other, advanced technological systems, when failure did occur, were more and more costly. Coping with the breakdown of a horse and carriage (a simple technology system) is one thing, but it is a completely different story when the breakdown occurs to an aircraft in flight. With the horse and carriage system, insurance was really secondary; with airplanes in flight, it becomes a very important factor.

- The new conditions of supply rigidity and vulnerability have then had the effect not only of slowing down the traditional rate of economic growth, but also of spilling into the overall social security system. Vulnerability is now a concept common to all sectors of insurance activity, from the production of oil to the overall organisation of health and pension funds. In the last ten years, this phenomenon has extended to the global 
financial market through the increase in volatilities in the way money is managed (and banks themselves are becoming increasingly risk-management oriented where interest, exchange and inflation rates are concerned).

Does all this mean that we are undergoing a fundamental crisis? My personal feeling is that it does not. The crisis has much more to do with the difficulty of adapting traditional methods of measuring economic reality, especially at the macro-economic level, to what is really happening. Simply put, the conditions for the development of the wealth of nations have changed. They have much to do today with the problems of managing services on the one hand and vulnerabilities on the other.

But there is a need for fundamental cultural adjustment; for accepting the idea that uncertainty and risk are not things we can get rid of, but are the very paving-stones of the way, major obstacles to be overcome or "managed" (as was "scarcity" the hallmark of the classical industrial revolution) in developing the wealth of nations.

At this point, the key cultural issue is that we are now experiencing a world transition where a philosophy of determinism has to be replaced by one of indeterministism. This type of revolution has already taken place in the natural sciences, but there is still some way to go in social sciences and in the economic philosophy behind economic policy formulations.

It is in this very broad context that we can identify a strategic role for insurance which was unimaginable only 30 years ago and which confronts the insurance industry as well as society as a whole with unparallelled challenges in managing risk.

\section{Insurability: a new economic "fundamental" issue}

Conventional economics has as yet not given sufficient attention to a phenomenon which is not only widely manifest but also of staggering dimension. Since the end of the 2nd World War, the real rate of growth of world insurance premium income has been on average consistently higher (at least $1 \%$ ) than the rate of growth of the global national income.

Over the last 20 years, insurance has undergone if not rebirth at least a fundamental revolution. It has become an essential pillar of all major economic policies and a main ingredient of development issues and problems, for example:

- Insurance has become the essential complement of all social security and savings policies.

- By vocation, and in several ways and through several institutions (including captive companies), insurance provides key professional methods for assessment, identification and management of technological, industrial and environmental risks.

- Insurance is an essential complement to any health policy.

- Entrepreneurial risk itself is increasingly conditioned, in all sectors, by an adequate understanding and control of pure risk, from the management of financial risk through the question of systemic risk. Everything seems to be pointing to one key issue: The identification of the level or the threshold of insurability, within which the private system can operate. Beyond that level of insurability, whatever the political ideology of a government, the public authorities or society at large have to step in. But as attempts are made to minimise the vulnerability (financial, economic and social) of governments and society, it is clear that the notion of insurability is moving, little by little, centrestage of economic policy-making in the future. Governments will, over time, increa- 
singly recognise that they have a vested interest in stimulating an efficient private insurance system in all fields in order adequately to develop economic policy. In fact, most governments in today's world are forced into privatising many activities in order to reduce their deficits. Once again this process concerns key policies like: Social security, the effects of natural catastrophes, industrial and environmental risks (with all the consequences they involve for liability), health insurance, crime and terrorism prevention (including fraud and moral-hasard related issues).

All these activities can be transferred to private institutions, to the extent that they fall within the limits of insurability.

There are of course essentially two levels of insurability:

- An upper level at which in theory all risks can be insured, provided they are sufficiently defined as a class and adequately quantified as far as their frequency and gravity are concerned; and

- A second level of insurability which is determined by the capacity of the insurance industry properly to cover these risks. The world capacity embraces both financial and management potential.

Whereas in the old world insurance could remain on the side-lines of economic activity, it is today fundamental that the profession succeeds in bringing home to governments (and to economic experts, scientists and institutions) that an adequate understanding of, an efficient policy for, the development of the private insurance sector is the key to success for their policies in the sectors concerned.

Of course any analysis of insurability involves specific issues like: the market and regulatory conditions for adequate capacity-building; the development of professionalism in risk selection (the improvement of rating management); regulations on solvency and fiscal conditions; the control of liabilities contracted in the past and their effect on the future solvency of insurance companies and institutions; reserve constitution in cases of extreme uncertainty. But such analysis also involves, as a matter of general economic policy, the setting up of economic incentives which facilitate economic development through the control of vulnerabilities. In economic terms, this means that any optimisation process has to consider on the one hand the cost of services from research to waste management, and on the other the risk management procedures relating to all manner of possible hazards.

Insurability is the line along which a new division of labour is being developed between private insurance and private industry in general on the one hand, and the public sector on the other.

It is not only in the interest of insurance today to fit into existing economic reality. But what is new, and no less fundamental, is that all economic institutions and society itself should wake up to the fact that they have a vested interest in being able to rely on an adequate and modern insurance industry. Were Adam Smith today to rewrite his book on "The Wealth of Nations", he would probably give to insurance the role that the textile industry enjoyed at the end of the 18th century. The challenge is a great one; the task of responding to it, formidable. 